\title{
Product development using vegetable fibers
}

\author{
C. R. Da Costa, A. Ratti \& B. Del Curto \\ Politecnico di Milano, Italy
}

\begin{abstract}
This article is a comprehensive review of the mechanical and tribological behavior of four plant fibers (hemp, kenaf, coconut and broom) and the product designs based on these plant fibers. The treatments as well as the chemical and physical characteristics of these types of plant fibers are investigated in order to understand their applications in the design field. The application of plant fibers has been the subject of many scientific and research projects, as well as many commercial projects. Data on these fibers are being collected and analyzed in order to arrange them and add new value for future applications. In most studies, natural fibers are used as replacement of traditional fibers in fiber-reinforced composites, or in the automotive sector, geo textiles and other engineering fields. The research carried out is organized so that the mechanical and chemicalphysical characteristics of these plant fibers can be used in conjunction with previous studies, to give a new scenario for design applications. In general, natural fibers have the advantages of biodegradability, low density, abundance and renewability, are non-toxic in nature, have useful mechanical properties and low cost. However, the main disadvantages of natural fibers are (i) the poor compatibility between fiber and matrix in composites, and (ii) the relative high moisture sorption. In addition, the project improves opportunities for sustainable goods through the development of design strategies for ecological sustainable products. The paper outlines a possible development of a product, which will be feasible thanks to the direct application of the results and tests of tools and methods adopted throughout the research.

Keywords: vegetable fibers, mechanical and chemical properties, product design, sustainability.
\end{abstract}




\section{Introduction}

The dependence on products based on petroleum fuels and the increase in environmental consciousness has enabled studies of new sustainable materials to replace existing ones. Environmental problems and regulations for cleaner processes have guided scientific research towards eco-composite materials.

The most viable way forward is the use of vegetable fibers as reinforcement, i.e., either long fibers, which are combined with a matrix that can be a polymer (epoxy, phenolic, polyester, polypropylene, and plastic), concrete, or short fibers, which are uniformly distributed and randomly oriented. Fibrous material content can increase the structural integrity of the composite material. Furthermore, vegetable fibers have biodegradable characteristics as renewable materials and contribute to the high performance of composite materials, that is, durability, low density, good mechanical properties, low cost and other which result in environmental advantages combined with enhanced technical performance. For instance, composite materials with vegetable fibers are also used in the automotive industry to make panels or components that provide sound proofing or damping.

On the other hand, there are many different fibers that are produced and used, such as hemp, coir, kenaf, or Spanish broom. Vegetable fibers are derived from sources such as the stalks, leaves, seeds and seed pods. With regard to other fibers, a coconut fiber, for example, has been obtained from the outer husk of the fruit and is used in a variety of applications such as doormats and civil engineering, that is, reinforce concrete applications or in materials for roofing. Also, it is used in the packaging industry and industrial designers are using it to make interior door panels, the ropes that are used in the nautical field as well as acoustic absorbers and sound barriers.

\section{Vegetable fibers}

\subsection{Spanish broom (Spartium junceum L.)}

The successful production of fibers from Spartium junceum $L$. has been known for many years, but the extraction process has low efficiency. This limited applications to scaling the Spanish broom fibers, despite the availability of the raw material and the highly attractive characteristics of the fibers, such as biodegradability and mechanical strength [1].

The main problem in the extraction of cellulose fibers from Spanish broom is the difficulty in removing the cortical cuticle; this results in a slow process, with limited applications in several fields [2].

Spanish broom fibers have advantages such as abundance and biodegradability; they do not generate toxic gases and mainly produce materials by combination with plastics (fiber mixed in a matrix). These fibers also have tensile strength and flexibility.

Spanish broom fibers in composites provide specific improvements, and have been used as reinforcement for polypropylene matrices [3]. However, Spanish 
broom has disadvantages such as poor compatibility with a hydrophobic polymer matrix, high affinity towards water, as well as relatively poor thermal stability. Consequently, weak interfaces are formed and this results in poor mechanical properties for the composites. These fibers need further treatments to improve their strength and fiber/matrix adhesion in fiber composites [4].

\subsection{Hemp (Cannabis sativa L.)}

Hemp can be cultivated in the climatic conditions experienced in temperate countries and hemp does not require any pesticide treatment whilst growing. However, hemp requires a government license for its cultivation; this imposes disadvantages compared to other fiber as flax.

Hemp harvesting is annual. It is a fiber from bast, with stem diameter 4 to $20 \mathrm{~mm}$, stem length 4 to $5-5 \mathrm{~mm}$. It can also be cultivated in climates with annual rainfall and high humidity. It is cultivated in countries such as Russia, Italy, China, Ex-Yugoslavia, Romania, Hungary, Poland, France, the Netherlands, UK and Australia. Its practical applications are for ropes, marine cordages, ships sails and paper.

Fiber extraction is done through maceration (10-15 days) and the separation of the fibers from the straw is then performed; this can be carried out mechanically [5].

\subsection{Coir (Coconut nucifera L.)}

The countries where coconut is cultivated are Brazil, India, Indonesia, Sri Lanka, Thailand, Malaysia, Philippines, Mexico, Kenya, Tanzania, Asia, Africa, Latin America and Pacific regions. Coconut plantations require temperatures between 20 and $32^{\circ} \mathrm{C}$, as well as high humidity and plenty of sunlight.

Coconut fiber is extracted from the outer husk of a coconut. There are two kinds of coconut fibers. Brown fiber is obtained from slightly ripened nuts and extracted from matured coconut; white fibers are obtained from immature nuts (green coconuts). Brown coir fiber contains more lignin than the cellulose of other fibers, and this high lignin content makes it resistant to weathering and resistant to abrasion, wet and dry conditions. Coconut fibers are available in the long fiber form, relatively short and mixed fibers. The leaves are used for roofs and mats, furniture, as husk for ropes, cordage and sail's fabric. These different types of fibers have different usage depending upon the application; for instance, the brown fiber is mostly used in engineering [6].

Coconut fibers have advantages as being resistant to fungi and rot. They are also excellent insulators against temperature and sound, flame-retardant, durable, renewable, among others. However, coconut fibers can have variations in properties, which makes difficult their frequent usage as construction materials.

Fibers dimensions vary with individual cells and depend on the type of species, maturity of the plant, location and extraction process. For example, the flexural and failure strength of the fiber is affected by the length to diameter ratio of the fiber. Its hollow cavity helps as an acoustic and thermal insulator; due to its presence, the bulk density of the fiber decreases [7]. 
The versatility and applications of coconut fibers in different fields is still being contested. But, it is concluded that these fibers have potential for use in composites and applied in different fields, for instance, in civil engineering (wall paneling systems); coconut fibers have been used as reinforcement in composites for non-structural components. However, there is a need for further studies regarding the behavior of coconut fiber reinforced concrete for use in columns of buildings as well as other applications.

\subsection{Kenaf (Hibiscus cannabinus L.)}

Kenaf is a member of the Malvaceae family; it is indigenous to Africa, and probably native to southern Asia. The stem contains short and long fibers [8].

Kenaf is cultivated in India, United States of America, Indonesia, Bangladesh, Malaysia, South Africa, Thailand, parts of Africa and small areas in southeast Europe.

This plant grows $1.5-3.5 \mathrm{~m}$ tall, with leaves $10-15 \mathrm{~cm}$ long. Its shape is variable. The fibers are in the bast (bark) and core (wood). The stem produces a coarser fiber (outer layer) and a finer fiber is found in the core. The main uses of kenaf fiber are for rope, paper, insulation and vehicle applications as material inside the door of cars.

Recently, industry has increased its dependence on petroleum based fuels and products. Because of this issue, there is a need to decrease the usage of these raw materials and to search for environmentally friendly products to replace the existing ones.

Vegetable fiber, such as kenaf is studied for use as non-woven mats in the automotive industry, textiles, reinforcement in composites. Some results of tests to determine the elastic modulus were compared with those from other synthetic fibers such as E-glass; these results showed possibilities to replace some synthetic materials by these fibers, since they were shown to have higher strength, lower cost and are environmentally more friendly [9].

\section{Chemistry, structure and morphology of the vegetable fiber}

The main chemical constituent of plant cells is cellulose (see fig. 1), hemicelluloses, lignin, pectin, waxes and other content in minor amounts. Cellulose is a polysaccharide polymer made up of glucose units and has the elements of the empirical formula $\left(\mathrm{C}_{6} \mathrm{H}_{10} \mathrm{O}_{5}\right) n$. Its chains are parallel to form bundles, denominated as microfibrils. Cellulose is the main chemical component of the primary plant cell wall and it is organized in the form of microfibrils. Cellulose is a complex carbohydrate made up of several glucose molecules connected end to end. Hemicellulose is a short and branched heterogeneous group of polysaccharides. In addition, the cell wall contains pectins and crosslinking glycans, which are groups of branched polysaccharides. Pectins and glycans are organized into a network with the cellulose, and the cross-linking glycans enhance the tensile strength of the cellulose, while the coextensive network of pectins supply the cell wall with the capability to resist compression. 


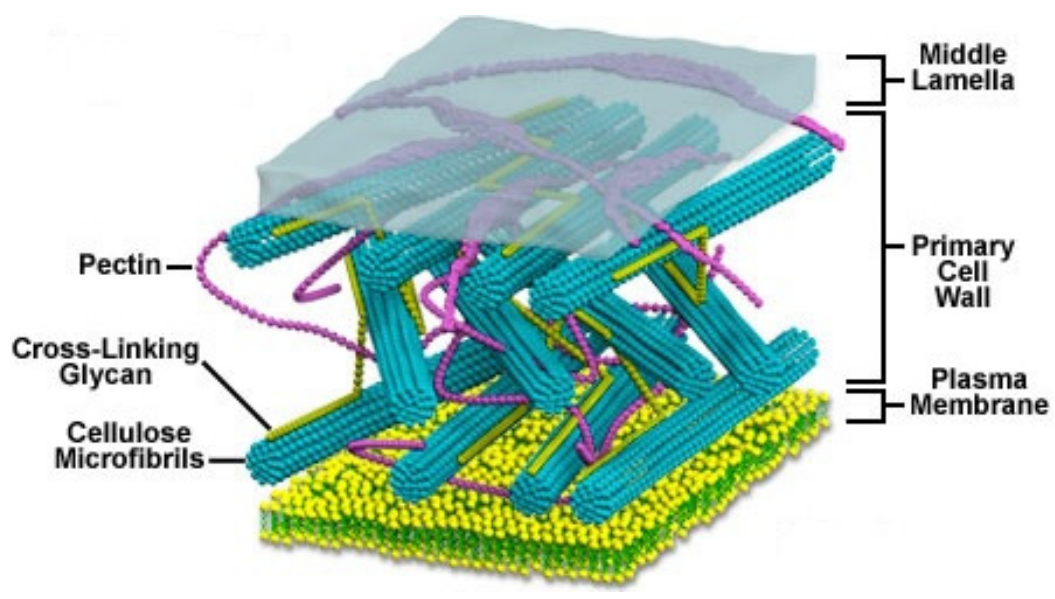

Figure 1: $\quad$ Plant cell wall structure [10].

The secondary plant cell wall, which is deposited inside the primary cell wall, has a composition almost identical to the primary cell wall. However, there are other additional substances such as lignin. This component, lignin, is a group of polymers of aromatic alcohols that are hard and confer considerable strength to structure of the secondary wall. Lignin is common in the secondary walls of xylem vessels, which are central in supplying structural support to plants. Another important characteristic of lignin is that it protects plant cell walls against attack by bacteria or fungi. Constituents as cutin, suberin, and other waxy materials are found in the plant cell wall. The region denominated middle lamella is associated with the cell walls of plants. It is an area rich in pectins and shared with neighboring cells; this cements them firmly together.

These contents and the conditions of the extraction processing methods interfere with the physical and mechanical properties of plant fibers. The chemical composition of vegetable fibers studied is summarized in table 1 below.

Table 1: Chemical composition of the selected vegetable fibers.

\begin{tabular}{|cccc} 
Fibers & Cellulose (\%) & Hemicelluloses (\%) & Lignin (\%) \\
\hline Hemp [11, 12] & $70.2-74.4$ & $17.9-22.4$ & $3.7-5.7$ \\
Kenaf [11, 12] & $53-57$ & $15-19$ & $5.9-9.3$ \\
Coir [13] & 68.9 & 16.8 & 32.1 \\
Spanish broom [2] & 44.5 & 70 & 18.5 \\
\hline
\end{tabular}

Table 1 shows a high amount of cellulose in the cell wall of the plant fibers; this allows an increase in fiber strength. The hemp fiber has a high cellulose 
content and can be used in the development of products that require tensile strength. If, for a product development, there is a need for protection against attack by bacteria or fungi, it is recommended that a high lignin content, as that encountered in coconut fibers, be used.

The structure of the cell wall can be seen in fig. 2; it is organized in layers, thus the cell wall of the fiber is not a homogenous membrane. Cell fibers have a diameter of 10 to $25 \mu \mathrm{m}$, having four layers of microfibrils. The cell is constituted externally of a layer called primary and internally has a secondary layer, which is made up of three layers $\left(\mathrm{S}_{1}, \mathrm{~S}_{2}\right.$ and $\left.\mathrm{S}_{3}\right)$. In the secondary layer $\mathrm{S}_{2}$, the microfribrils are aligned at an angle $\theta$ (the angle between the fiber axis and the microfibrils) with respect to the longitudinal axis of the cell [14].

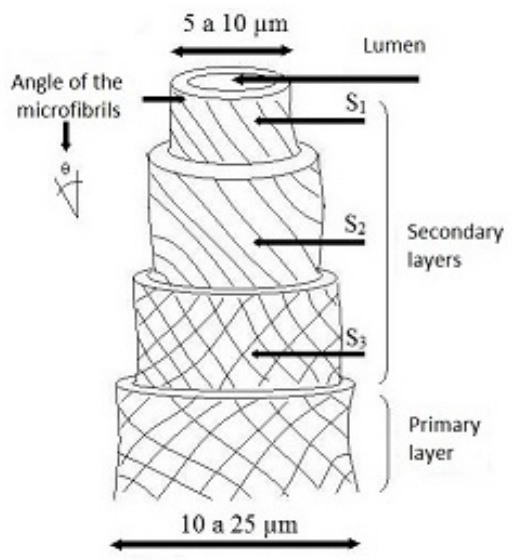

Figure 2: Structure constitution of cell wall of plant fiber [15].

There is the middle lamella (M) that determines the mechanical properties of the fiber. This layer M consists of a several "wound cellular microfibrils" formed by long chains of cellulose molecules [16].

The outer secondary cell wall $\left(\mathrm{S}_{3}\right)$ has the same thickness as that of the primary wall $(\mathrm{P})$ and is composed of four to six lamellae spiralling in opposite directions. The cell wall $\left(\mathrm{S}_{2}\right)$ constitutes the main bulk and the microfibrils of this part make an angle of around 10 to $20^{\circ}$. The inner layer $\left(S_{1}\right)$ is not well developed and it has not significant technological importance. However, the $\mathrm{S}_{2}$ layer has important mechanical properties such as its elasticity modulus [16].

Basic parameters such as cellulose content and the spiral angle characterize the mechanical behavior of plant fibers. When the cellulose content increases, then the tensile strength of the fibers increase too. If the angle of helix axis of the fibers decreases, the tensile strength, respectively, increases [17].

Vegetable fibers can be classified morphologically according to the part of the plant from which they are obtained [5]:

- Bast or phloem fibers (soft fibers); these fibers are enclosed in the inner bast tissue or bark of the stem of the dicotyledonous plants and help to 
hold the plant erect. These fibers are freed from the bast tissues through the maceration process.

- Leaf fibers (hard fibers) are parts of the leaves' fibro vascular system. They are extracted by scraping the pulp from fibers with a knife, manually or mechanically.

- Seed and fruit fibers are produced by the plant to protect the seed and fruit. The fibers are extracted when the fruit is husked and macerated.

\section{Advantages of using polymeric materials reinforced with natural fibers}

A composite material is constituted of two phases; in other words, it consists of one or more discontinuous phase embedded in a continuous phase. This discontinuous phase, called the reinforcing material, is usually harder and stronger than the continuous phase and improves the overall mechanical properties of the matrix. While the continuous phase, called the matrix, is usually more ductile and less hard and it is a dispersed phase which shares the applied loads. The matrix can be made of materials such as polymers, metals or ceramics [18].

The characteristics of composites depend on the properties of their constituent materials, their distribution and the interaction among them. The geometry of reinforcement (shape, size and distribution), the shape of the discontinuous phase (spherical, cylindrical, rectangular or in the form of platelets), and the volume fraction determine the interfacial area; the concentration, normally measured as volume or weight fraction, determines the contribution of a single constituent to the overall properties of the composites.

The use of composites is due to their overall properties being superior to those of their individual components. For reinforcing polymers, fibers can be used; these are the main source of strength with the matrix keeping all fibers together in shape and transferring stresses between the reinforcing fibers. Commonly, fiber reinforcing includes carbon fibers, glass fibers and asbestos, among others. In addition, common matrix materials are epoxy, polyester and polyurethane, among others.

Composite materials have some advantages such as improved tensile strength and torsional stiffness as well as impact properties and lower embedded energy when compared with structural metallic materials (like aluminum and steel). During operation, composite materials are less noisy than metals and provide lower vibration transmission. Composites have long life when subjected to fatigue loading and impact, excellent corrosion resistance and fire retardancy. In addition, an important factor for companies and the environment is that composites have reduced life cycle cost compared to metals [18].

Polymeric materials reinforced with synthetic fibers such as glass and carbon have advantages such as high stiffness and strength to weight ratios compared to conventional construction materials such as wood, concrete and steel. However, the use of synthetic fiber-reinforced polymer composites has a tendency to decline due to their high cost and adverse environmental impact. There is an 
increased interest in using natural fibers as reinforcement in plastics as substitutes to conventional synthetic fibers in some structural applications. Renewable raw materials resources are environmentally friendlier; they do not cause health problems and are shown to be high performance materials.

The increasing demand for environmentally friendly materials and the desire to reduce the cost of using traditional materials, i.e., to substitute carbon, glass and aramid fibers in reinforced petroleum-based materials, new bio-based composites have been recently developed for several industrial applications. Many investigations are focusing on natural fiber composites, which are formed of natural or synthetic resins, reinforced with natural fibers.

Natural fiber characteristics such as renewability, low cost, recyclability and biodegradability make possible their use as reinforcement in composites. Other characteristics such as availability, low density and satisfactory mechanical properties make them attractive alternatives to glass and carbon fibers for use in the manufacture of composites.

Natural fibers can be effective material constituents for applications in building and construction industries, such as, in panels for ceiling, boards, walls, windows, doorframes, roofs, pre-fabricated buildings, storage boxes, furniture (chairs, tables, etc.), electrical appliances, suitcases, helmets, boats and toys. The use of natural fibers results in features such as low density; there can be a product weight reduction of around 10 to $30 \%$ [18]. In addition, they exhibit favorable mechanical properties, high stability, good thermal and acoustic insulation as well as health benefits compared to glass fibers during the production process.

\section{Mechanical properties of the selected vegetable fibers}

Vegetable fibers for technical applications require research towards a better understanding of which parameters are the ones that influence and optimize their performance. An important issue is the mechanics of the processes used to extract the fibers from plants; this has a significant effect on the mechanical performance of the fiber.

In recent years, vegetable fibers have gained ground as substitutes of glass fibers in composite components. Vegetable fibers like hemp, kenaf, coir are relatively cheap and have better stiffness per unit weight. Structural applications and semi-finished materials manufactured using vegetable fibers have problems such as low impact strength and poor moisture resistance. For this reason, the fibers need further pre-treatment to improve their function within the matrices [19]. The most important physical and mechanical properties are summarized in table 2 .

\section{Applications of selected vegetable fibers}

Considering the performance of composite materials in terms of maintenance, cost and durability, the use of vegetable fiber reinforced composites in the automotive field or as construction materials (wall paneling, roofs) has large 
Table 2: $\quad$ Properties of selected vegetable fibers.

\begin{tabular}{cccccc} 
Properties & E-glass & Hemp & Coir & Kenaf [9] & Spanish Broom \\
$\begin{array}{c}\text { Density } \\
\text { g/cm }\end{array}$ & 2.55 & 1.48 & 1.25 & 0.9 & $1.45[20]$ \\
$\begin{array}{c}\text { Tensile } \\
\text { Strength * }\end{array}$ & 2400 & $550-900$ & 220 & 340 & $700[21]$ \\
$\begin{array}{c}10 \mathrm{E} 6 \mathrm{~N} / \mathrm{m}^{2} \\
\text { E-modulus } \\
(\mathrm{GPa})\end{array}$ & 73 & 70 & 6 & 1.4 & $20[21]$ \\
$\begin{array}{c}\text { Elongation } \\
\text { at Failure } \\
(\%)\end{array}$ & 3 & 1.6 & $15-25$ & - & $2.7 \%[22]$ \\
\hline
\end{tabular}

*Tensile strength strongly depends on type of fiber, being a bundle or a single filament.

potential and is fundamental for achieving sustainability. Currently, the application of plant fiber composites in the automotive sector is not being much explored, but in other fields, plant fibers are found to be applicable in the civil engineering, for instance for thermal insulation (roof insulation boards) and improving acoustics (sound-absorbing panels).

Some mechanical properties of vegetable fibers prevent them from being used in high-performance applications; for instance, where carbon fiber is used as the reinforcement in a composite. However, plant fibers can be used as replacement of glass fibers due to their properties such as stiffness, strength, lower weight, low cost, easier recyclability [19].

Vegetable fibers can also be used as a replacement of synthetic fibers in reinforced composites. They can be molded into sheets, pallets, structural sections, boards and other shapes. Due to their adequate tensile strength and good specific modulus, they leverage the right potential for usage in composites.

Although the tensile strength and Young's modulus of some plant fibers are lower than those of glass fibers, the specific modulus of some plant fibers can be superior to that of glass. This characteristic together with the lower cost and renewable nature of plant fibers, as well as the much lower energy requirement for their production also make them attractive as reinforcing fibers in composites.

\section{Conclusions}

The mechanical properties of vegetable fibers are attractive to the composites industry. With advantages such are renewability, biodegradability and low weight, the practical application of these plant fibers has received increased attention from academic and industrial environments, civil engineering, automotive and packaging industries, among others.

Assessing the importance of composites as advanced performance materials in various sectors such as automobile, building, construction and marine 
engineering, the vegetable fibers have great possibilities of application and further studies to expand their usage in composites are essential.

The role of natural fibers in composites is positive since their use demonstrates low abrasion, reduction in energy consumption, better vibration, dampening capabilities, better insulation and sound absorption properties, better degradation when time life is exhausted, reduction of the dependence on petroleum based products, and other characteristics. However, some limitations must be overcome in order to explore the complete potential of vegetable fibers to expand their field of applicability. The usage of vegetable fibers has given some marvelous products, and there is still a possibility of the invention of new products containing vegetable fibers with improved results.

\section{Acknowledgements}

This work is supported by the CNPq (Conselho Nacional de Desenvolvimento Científico e Tecnológico - "National Counsel of Technological and Scientific Development"), (Project n 245403/2012-4).

\section{References}

[1] Mohanty, D.A.K., Mistra, M., \& Drzal, L.T., (eds). Natural Fibers, Biopolymers and their Biocomposites, CRC Press: London, 2005.

[2] Gabriele, B., Cerchiara, T., Salermo, G., Chidichimo, G., Vetere, M.V., Alampi, C., Gallucci, M.C., Conidi, C. \& Cassano, A., A new physicalchemical process for the efficient production of cellulose fibers from Spanish broom (Spartium junceum L.). Bioresource Technology, 101, pp. 724-729, 2010.

[3] Avella, A., Casale, L., Dell'Erba, R. \& Martuscelli, E., Broom fibers as reinforcement for thermoplastic matrices. Macromolecular Symposia, 127, pp. 211-218, 2011.

[4] Cassano, R., Trombino R., Bloise, S., Muzzalupo, E., Iemma, R., Chidichimo, F. \& Picci, N., New broom fiber (Spartium junceum L.) derivatives: preparation and characterization. Journal of Agricultural and Food Chemistry, 55(23), pp. 9489-9495, 2007.

[5] Pritchard, M., Sarsby, R.W. \& Anand, S.C., Textiles in civil engineering. Part 2 - natural fibre geotextiles (Chapter 14). Textbook of Technical Textiles, eds. A.R. Horrocks \& S.C. Anand, Woodhead Publishing Limited: Cambridge, pp. 372-406, 2000.

[6] Majid, A., Coconut fibre: a versatile material and its applications in engineering. Journal of Civil Engineering and Construction Technology, 2(9), pp. 189-197, 2011.

[7] Flower, P.A., Hughes, J.M. \& Melias, R., Review bio composites: technology, environmental credentials and market forces. Journal of the Science of Food and Agriculture, 86, pp. 1781-1789, 2006.

[8] Raji, J.A., Intercropping kenaf and cowpea. African Journal of Biotechnology, 6(24), pp. 2807-2809, 2007. 
[9] Zampaloni, M., Pourboghrat, F., Yankovich, S.A., Rodgers, B.N., Moore, J., Drzal, L.T., Mohanty, A.K. \& Misra, M., Kenaf natural fiber reinforced polypropylene composites: a discussion on manufacturing problems and solutions. Composites, pp. 1569-1580, 2007.

[10] Davidson, M.W. Plant cell wall. Molecular Expressions website. Online. http://micro.magnet.fsu.edu/cells/plants/cellwall.html

[11] Williams, G.I. \& Wool, R.P., Composites from natural fibers and soy oil resins. Applied Composite Materials, 7(5-6), pp. 421-432, 2000.

[12] Bogoeva-Gaceva, G., Avella, M., Malinconico, M., Buzarovska, A., Grozdanov, A., Gentile, G. \& Errico, M.E., Natural fiber eco-composites. Polymer Composites, 28, pp. 98-107, 2007.

[13] Asasutjarit, C., Hirunlabh, J., Khedari, J., Charoenvai, S., Zeghmati, B. \& Shin, U.C., Development of coconut coir-based lightweight cement board. Construction and Building Materials, 21(2), pp. 2787-2788, 2007.

[14] Da Costa, C.R., Boueri, J.J., Baruque Ramos, J. \& Sanches, R.A., Chemical composition and mechanical properties of fiber Cocus Nucifera 1. Proc. of the 13th AUTEX World Textile Conference, Dresden, Germany, 2013.

[15] Farias, G.G., Modificação superficial de fibras de coco por tratamento a plasma para utilização como fase de reforço em amido termoplástico. Projeto de Graduação apresentado ao Curso de Engenharia de Materiais da Escola Politécnica, Universidade Federal do Rio de Janeiro, 2012.

[16] Farsi, M., Thermoplastic matrix reinforced with natural fibers: a study on interfacial behavior. Some Critical Issues for Injection Molding, ed. J. Wang, Intech, pp. 225-250, 2012.

[17] Cristaldi, G., Latteri, A., Recca, G. \& Cicala, G., Composites based on natural fibre fabrics, University of Catania- Department of Physical and Chemical Methodologies for Engineering, 2010.

[18] Prakash, T., Processing and characterization of natural fiber reinforced polymer composites, Bachelor Thesis, Department of Mechanical Engineering, National Institute of Technology Rourkela, 2009.

[19] Nangia, S., Srikanth, G., Mittal, A. \& Biswas, S., Composites in civil engineering. Technology Information, Forecasting and Assessment Council- Department of Science and Technology, Govt. of India. Online. www.tifac.org.in/index.php?option $=$ com_content\&id=544: composites-incivil-engineering\&catid=85:publications $\$$ Itemid $=952$.

[20] Fallico, C., Troisi, S., Molinari, A. \& Rivera, M.F., Characterization of broom fibers for PRB in the remediation of aquifers contaminated by heavy metals. Biogeosciences, 7, pp. 2545-2556, 2010.

[21] Angelini, L.G., Levita, G., Fontanelli, D. \& Bozzi, C., Ramie and Spanish Broom fibres for composite materials: agronomical aspects, morphology and mechanical properties. Industrial Crops and Products, 11, pp. 145$161,2000$.

[22] Mark, H.F., Encyclopedia of Polymer Science and Technology, 12, New York: John Wiley \& Sons, 2004. 